\title{
HUBUNGAN TINGKAT STRES DENGAN SINDROM PREMENSTRUASI PADA MAHASISWI DIII KEBIDANAN SEMESTER 2 UNIVERSITAS ‘AISYIYAH YOGYAKARTA
}

\author{
Nurul Hidayah Bohari ${ }^{1^{*}}$, Haerani, Fasilah Basri ${ }^{1}$, Misnawaty ${ }^{1}$, Mudyawati Kamaruddin ${ }^{1^{*}}$ \\ ${ }^{1}$ Program Studi Kebidanan,Akademi Kebidanan Tahirah Al Baeti Bulukumba, Sulawesi Selatan \\ *Corresponding author: Telp: +628 85343788567, email: nuruhidayahbohari@gmail.com; \\ mudya07@gmail.com
}

\begin{abstract}
ABSTRAK
Sindrom premenstruasi menjadi masalah pada wanita dan gejala atau keluhan yang sering muncul adalah gejala fisik dan gejala emosional. Dampak dari sindrom premenstruasiadalah gangguan aktifitas harian, seperti penurunan produktifitas kerja, sekolah, dan hubungan interpersonal penderita. Disamping itu sindrom premenstruasi yang berat juga dapat berhubungan dengan kasus bunuh diri yang tinggi, tingkat kecelakaan, dan masalah kejiwaan akut atau faktor stress. Tujuan penelitian ini untuk mengetahui hubungan antara tingkat stres dengan sindrom premenstruasi pada mahasiswi DIII kebidanan semester 2 Universitas 'Aisyiyah Yogyakarta. Penelitian ini menggunakan deskriptif korelasi dengan pendekatan waktu cross sectional. Populasi pada penelitian ini adalah mahasiswi DIII kebidanan semester 2 Universitas 'Aisyiyah Yogyakarta tahun 2017 dengan metode pengambilan sampel menggunakan Proportioned Random Sampling didapatkan sebanyak 103 responden, alat ukur dengan kuesioner dan uji statistik Kendall tau dengan taraf signifikansi 0.05 atau 5\%.Hasil analisis diperoleh nilai $\mathrm{p}$ sebesar 0,002 berarti $(\mathrm{p}<0,05)$ maka terdapat hubungan antara tingkat stres dengan sindrom premenstruasi pada mahasiswi D3 kebidanan semester 2 Universitas 'Aisyiyah Yogyakarta. Kesimpulan yang dapat diangkat adalah terdapat hubungan antara tingkat stres dengan sindrom premenstruasi pada mahasiswi DIII kebidanan semester 2 Universitas 'Aisyiyah Yogyakarta $(\mathrm{p}=0,002 ; \mathrm{p}<0,005 ; \mathrm{r}=0,298)$. Mahasiswi disarankan agar dapat mengendalikan stres yang berlebih serta melakukan aktifitas positif yang dapat mengurangi stres.
\end{abstract}

Kata Kunci : Mahasiswi, Sindrom Premenstruasi, Tingkat Stres

\section{ABSTRACT}

Abstract :Premenstrual syndrome is a problem in women and symptoms or complaints that often arise are physical symptoms and emotional symptoms. The impact of premenstrual syndrome is the disruption of daily activities, such as decreased work productivity, school, and interpersonal relationships. In addition, severe premenstrual syndrome may also be associated with high suicide cases, accident rates, and acute psychiatric problems or stress factors.The study aims to investigate the correlation between stress level and premenstrual syndrome of semester 2 DIII Midwifery School Students at 'Aisyiyah University of Yogyakarta.The study is descriptive correlation with cross sectional time approach. The population in this research was the second semester $2^{\text {nd }}$ semester students of 'Aisyiyah University of Yogyakarta in 2017. The sampling method used Proportioned Random Sampling as many as 103 respondents. The instrument was questionnaire. The statistic test was Kendall tau with significance level of 0.05 or $5 \%$.The analysis obtained $p$ value of 0.002 which means that $(p<0.05)$. Therefore, there is a correlation between stress level and premenstrual syndrome of semester 2 students of DIII Midwifery School at 'Aisyiyah University of Yogyakarta.There is a correlation between stress level and premenstrual syndrome of semester 2 students of DIII Midwifery School at 'Aisyiyah 
University of Yogyakarta ( $p=0,002 ; p<0,005 ; r=0,298)$. Students are suggested to be able to control excessive stress and do positive activities that can reduce stress.

Keywords: Premenstrual Syndrome, Students, Stress Level

\section{PENDAHULUAN}

Kesehatan reproduksi merupakan salah satu hal penting dalam siklus hidup wanita. Salah satu periode dalam daur kehidupan kesehatan reproduksi adalah remaja. Perempuan dalam hal ini remaja memiliki berbagai masalah kesehatan reproduksi disetiap bulannya dengan menstruasi atau haid mereka.Setiap bulannya, wanita usia subur akan mengalami menstruasi. Sebelum terjadinya menstruasi, selama 7-10 hari seorang wanita akan mengalami gejala-gejala perubahan emosional maupun fisik atau yang sering disebut sindrom premenstruasi dan akan mereda ketika menstruasi dimulai. ${ }^{1,2}$

Faktor psikologis seperti stres akan memperberat gangguan sindrom premenstruasi. Hal ini sangat mempengaruhi kejiwaan dan koping seseorang dalam menyelesaikan masalah, dimana stres memiliki peran penting dalam tingkat gejala sindrom premenstruasi. $^{3}$

Berdasarkan laporan WHO (World Health Organization), sindrom premenstruasi memiliki prevalensi lebih tinggi di negaranegara asia dibandingkan dengan negaranegara barat (Mohamadirizi \& Kordi, 2013, hlm 2). Hasil penelitian American College Obstetricians and Gynecologists, ${ }^{4}$ di Sri Lanka tahun 2012, melaporkan bahwa gejala sindrom premenstruasi dialami sekitar $65,7 \%$ remaja putri. Hasil studi Mahin Delara di Iran (2012), ditemukan sekitar 98,2\% perempuan yang berumur 18 hingga 27 tahun mengalami paling sedikit 1 gejala sindrom premenstruasi derajat ringan atau sedang.

Berdasarkan data yang diperoleh dari Departemen Kesehatan tahun 2014 tentang prevalansi sindrom premenstruasi di Indonesia, diperoleh hasil sebanyak $40 \%$ wanita Indonesia mengalami sindrom premenstruasi dan sebanyak 2-10\% mengalami gejala berat. ${ }^{6}$ Menurut Emilia (2008) dari 260 orang wanita usia subur, ditemukan sebanyak 95\% memiliki setidaknya satu gejala sindrom premenstruasi, dengan tingkat sindrom premenstruasi dari sedang hingga berat sebesar $3,9 \% .^{6-8}$

Kemudian Nabi shallallahu 'alaihi wa sallam bersabda,

$$
\text { اللَّهُ عَلَى بَنَاتِ آدَمَ، إِنَّ هَذَا أَمْرُ كَتَبَهُ }
$$

Artinya : "Sesungguhnya haid adalah perkara yang telah Allah tetapkan untuk putri Adam."(HR. Bukhari 294 dan Muslim 1211). ${ }^{9}$

Ayat di atas menjelaskan bahwa haid merupakan peristiwa yang telah Allah tetapkan atas kaum wanita keturunan Adam.

Bagi beberapa wanita gejala sindrom premenstruasi dapat terjadi cukup parah, sehingga dapat menimbulkan dampak yang merugikan. Umumnya dampak dari sindrom premenstruasi tersebut adalah gangguan aktifitas harian, seperti penurunan produktifitas kerja, sekolah, dan hubungan interpersonal penderita. ${ }^{10}$ Disamping itu sindrom premenstruasi yang berat juga dapat berhubungan dengan kasus bunuh diri yang tinggi, tingkat kecelakaan, dan masalah kejiwaan akut atau faktor stres. ${ }^{1}$

Berdasarkan latar belakang tersebut maka peneliti tertarik untuk melakukan penelitian mengenai hubungan antara tingkat stres dengan sindrom premenstruasi pada mahasiswi DIII Kebidanan semester 2 Universitas 'Aisyiyah Yogyakarta.

\section{METODOLOGI}

Jenis penelitian ini adalah penelitian kuantitatif dengan menggunakan design deskriptif korelasi dengan pendekatan waktu Cross sectional.Variabel yang terkait dalam penelitian ini, yaitu variabel independent/ variabel bebas adalah tingkat stres dan variabel dependent/ terikat dalam penelitian ini adalah sindrom premenstruasi.

Populasi yang diteliti dari penelitian ini adalah mahasiswi DIII kebidanan semester 2 Universitas 'Aisyiyah Yogyakarta tahun 2017 yang berjumlah 139 orang. Sedangkan metode pengambilan sampel dalam penelitian ini 
menggunakan Proportioned Random Sampling yaitu berjumlah 103 orang.

Alat pengumpulan data yang digunakan untuk variabel tingkat stres adalah kuesioner DASS 42 yang telah di ubah ke versi Bahasa Indonesia oleh Evelina Debora Damanik dan telah melewati uji validitas dan reliabilitas dengan hasil 0,8806, sedangkan alat pengumpulan data yang digunakan untuk variabel sindrom premenstruasi adalah kuesioner yang dibuat oleh peneliti yang diadopsi dari Daily Menstrual Symptom Rating Scaledengan hasil 0,853. Pada penelitian ini uji statistik yang digunakan untuk uji hipotesis adalah Kendal Tau.

\section{HASIL DAN PEMBAHASAN}

\section{HASIL}

Tabel 1 Hubungan Tingkat Stres dengan Sindrom Premenstruasi Pada Mahasiswi DIII Kebidanan Semester 2 Universitas 'Aisyiyah Yogyakarta tahun 2017.

\begin{tabular}{lccccccc}
\hline & \multicolumn{8}{c}{ Sindrom Premenstruasi } & \\
Tingkat Stres & \multicolumn{2}{c}{ Ringan } & \multicolumn{2}{c}{ Sedang } & \multicolumn{2}{c}{ Berat } & pvalue \\
& F & $\%$ & F & $\%$ & F & $\%$ & \\
\hline Ringan & 65 & 83,3 & 11 & 14,1 & 2 & 2,6 & \\
Sedang & 7 & 46,7 & 8 & 53,3 & 0 & 0 & 0,002 \\
Berat & 6 & 66,7 & 2 & 22,2 & 1 & 11,1 & \\
Sangat Berat & 0 & 0 & 0 & 0 & 1 & 100,0 & \\
Jumlah & 78 & 75,7 & 21 & 20,4 & 3,9 & 100,0 & \\
\hline Sumber : Data Primer, 2017 & & & & &
\end{tabular}

Berdasarkan hasil kuesioner tingkat stres yang diberikan kepada mahasiswi DIII Kebidanan semester 2 Universitas 'Aisyiyah Yogyakarta penyebab stres terbanyak berasal dari perasaan sehari-hari mahasiswi, seperti yang diketahui bahwa responden penelitian ini adalah perempuan. Perempuan cenderung lebih banyak dikontrol oleh perasaan mereka dalam menghadapi masalah.

Stres pada remaja disebabkan oleh berbagai faktor, tetapi faktor yang paling banyak mempengaruhi remaja berhubungan dengan orangtua, akademik, dan teman sebaya.Sumber stres pada remaja perempuan sering merasa cemas ketika sedang menghadapi masalah. ${ }^{11}$

Menurut peneliti setiap mahasiswi tentunya memiliki pengalaman dan cara yang berbeda-beda dalam mengelola stres yang mereka alami walaupun dengan stressor yang sama, sehingga tingkat stres yang dialami oleh mahasiswi juga bervariasi tergantung dari pengalaman stres akademik dari mahasiswi tersebut. Aktifitas di kampus yang tiap saat dilakukan oleh mahasiswi DIII Kebidanan semester 2 Universitas 'Aisyiyah Yogyakarta antara lain proses perkuliahan mulai dari pagi hingga malam, yang didalamnya ada kuliah pakar, tutorial, praktikum di Skill lab, dan tidak lepas dari tugas-tugas yang diberikan oleh dosen. Kondisi tersebut tentu menuntut mahasiswi untuk bertanggung jawab menyelesaikan tugas secara mandiri dan mampu menyelesaikan tugas-tugas yang dibebankan tepat waktu.

Selain itu berdasarkan hasil penelitian didapatkan hasil bahwa dari 103 responden terdapat 78 responden $(75,7 \%)$ yang mengalami sindrom premenstruasi ringan, dan yang paling sedikit terdapat 4 responden $(3,9 \%)$ yang mengalami sindrom premenstruasi berat. Hal ini didukung oleh beberapa fasilitas yang didapatkan di Universitas 'Aisyiyah Yogyakarta, diantaranya 
terdapat lapangan yang dapat digunakan untuk berolahraga yaitu lapangan basket serta lapangan voly, terdapat kantin dan minimarket yang menjual makanan dan minuman yang sehat, kemudian terdapat klinik kesehatan yang dimana mahasiswi bisa berkonsultasi mengenai kesehatannya dan terbuka setiap hari senin hingga sabtu dan langsung ditangani oleh seorang dokter.

Tingginya kejadian sindrom premenstruasi ini disebabkan karena masa remaja merupakan masa transisi dari masa anak-anak menjadi dewasa. Dimana remaja adalah masa dimana seseorang berada pada rentang usia 11-21 tahun. ${ }^{12}$ Pada masa inilah terjadi perubahan sangat signifikan, tidak hanya dari fisik, namun dari fisiologis dan psikologis pula.

Menurut Nourjah (2008) Kualitas hidup perempuan khususnya remaja putri salah satunya dipengaruhi oleh sindrom premenstruasi.Dengan adanya gangguan sindrom premenstruasi, konsentrasi belajar, absensi, hubungan dengan lingkungan sosial serta kaitan secara tidak langsung pada keadaan ekonomi dapat terganggu.Setiap perempuan yang mengalami sindrom premenstruasi membutuhkan penanganan yang berbeda.

Di lihat dari segi hubungan antara kedua variabel tersebut dalam penelitian ini menunjukkan adanya hubungan dari perhitungan Kendall Taudiperoleh nilai signifikansi $p$-value sebesar0,002 berarti ( $\mathrm{p}<$ $0,05)$ sehingga dapat dinyatakan bahwa ada hubungan antara tingkat stres dengan sindrom premenstruasi pada mahasiswi DIII Kebidanan semester 2 Universitas 'Aisyiyah Yogyakarta.

\section{PEMBAHASAN}

Hasil penelitian menunjukkan bahwa sebagian besar responden mengalami sindrom premenstruasi ringan dan tingkat stres ringan sebanyak 65 responden (83.3\%).Hal ini didukung dengan fasilitas-fasilitas yang didapatkan di Universitas 'Aisyiyah Yogyakarta, dimana stres ataupun sindrom premenstruasi yang dialami dalam batas ringan. Fasilitas yang didapatkan seperti mengaji secara bersama-sama sebelum memulai KBM (kegiatan belajar mengajar), sholat berjamaaah ketika waktu shalat wajib tiba, terdapat klinik kesehatan, dan masingmasing mahasiswi memiliki pembimbing akademik yang akan memberikan bimbingan ataupun pendapat, masukan, dan kritik apabila mahasiswi memiliki masalah akademik yang tidak dapat diselesaikan oleh mahasiswi tersebut, serta lapangan olahraga.

Hasil analisis bivariat tingkat stres dengan sindrom premenstruasi pada mahasiswi DIII kebidanan semester 2 Universitas 'Aisyiyah Yogyakarta menunjukkan ada hubungan yang bermakna antara tingkat stres dengan sindrom premenstruasi pada mahasiswi DIII kebidanan semester dengan nilai $\mathrm{p}=0,002$ berarti $(\mathrm{p}<$ $0,05)$ Jadi hal ini hipotesis kerja diterima.

Hasil yang sejalan juga dihasilkan oleh penelitian lainnya yang menemukan bahwa terdapat hubungan positif dengan korelasi yang sedang antara tingkat stres dengan kejadian sindrom premenstruasi. ${ }^{5}$

Faktor psikis, yaitu stres sangat besar pengaruhnya terhadap kejadian sindrom premenstruasi. Gejala-gejala sindrom premenstruasi akan semakin berat jika di dalam diri seorang wanita terus menerus mengalami tekanan.

Siregar (2013) dalam penelitiannya mengatakan bahwa mahasiswa kedokteran Universitas Sumatra Utara ditemukan bahwa stres menjadi pemicu terjadinya sindrom premenstruasi, dibuktikan dengan hasil tes $\mathrm{chi}^{-}$ square yang menunjukkan hubungan antara stres dan sindrom premenstruasi sangat signifikan dengan nilai $p$ value 0,000 .Ada hubungan yang bermakna antara stres dengan PMS $(\mathrm{p}=0,036<$ dari 0,05).

Olahraga berupa lari di katakan dapat mengurangi keluhan. Berolahraga dapat mengurangi stress dengan cara memilih waktu untuk keluar dari rumah dan pelampiasan untuk melepas marah atau kecemasan yang terjadi. Defisiensi endorphin merupakan salah satu penyebab sindrom premenstruasi. Endorphin dibuat dalam tubuh yang terlibat sensasi euphoria dan nyeri. Olahraga dapat membuat hormon endorphin muncul yang 
membuat perasaan menjadi tenang dan santai ${ }^{13}$.

Menurut Yamamoto et al (2009) Prevalensi mahasiswi yang mengalami gejala PMS, nyeri haid, dan siklus haid tidak teratur adalah 79\%, 79\%, dan 63\%.Stres psikososial secara umum berpengaruh dengan gejala PMS dan pengalaman siklus menstruasi yang tidak teratur pada mahasiswi menandakan adanya perubahan pada wanita sebagai akibat dari stres yang terkait dengan perubahan fungsi menstruasi.

Siti Damayanti (2013) dalam penelitiannya berpendapat bahwa Hasil dari penelitian ini adalah stres dan pola konsumsi ada hubungannya dengan premenstrual syndrom, sedangkan pola olah raga tidak ada hubungannya dengan premenstrual syndrom.

Suheimi (2008), mengatakan bahwa penyebab terjadinya gejala sindrom premenstruasi adalah interaksi yang kompleks antara hormon, nutrisi esensial dan neurotransmitter yang dikombinasikan dengan stres psikologis.Jadi sindrom premenstruasi merupakan keadaan abnormalitas dari wanita untuk beradaptasi terhadap perubahan fluktuasi hormonal bulanannya. Kehidupan yang penuh stres akan memperparah gejalagejala fisik maupun psikologis dari sindrom premenstruasi ini.

Ada bukti baru yang menunjukkan bahwa rendahnya kadar serotonin, suatu senyawa kimia penting yang diproduksi oleh otak merupakan penyebab utama respon sindrom premenstruasi. Serotonin adalah pemain kunci yang berperan pada banyak proses tubuh dan siklus.

Serotonin membantu siklus tidur dan metabolisme karbohidrat dan mempengaruhi pengaturan estrogen dan progesteron wanita dengan sindrom premenstruasi memiliki kadar serotonin yang rendah dan bervariasi, sehingga dapat menyebabkan ovulasi tertunda atau lebih awal dan memicu suatu ketidakseimbangan hormon estrogen dan progesteron. ${ }^{3}$

Serotonin mempengaruhi ovulasi dan ovulasi yang kurang sempurna menurunkan kadar serotonin di otak yang menyebabkan keluhan hebat yang dikenal sebagai sindrom premenstruasi. Penjelasan mengenai "ovulasi yang kurang sempurna" memperkuat alasan penggunaan terapi hormon yang sukses digunakan untuk menekan dan mengatur ovulasi dan mengoreksi ketidakseimbangan hormon yang menyebabkan gejala sindrom premenstruasi.Semenjak stres dikenal dapat mengacaukan pola ovulasi, teori ini menempatkan stres sebagai satu faktor utama pada penyebab sindrom premenstruasi. ${ }^{3}$

Ketidakseimbangan antara hormon estrogen dan progesteron sebelum menstruasi mempengaruhi aktifitas serotonin, sehingga produksi serotonin didalam tubuh menurun. Akibat dari rendahnya produksi serotonin akan mempengaruhi terjadinya ovulasi seperti proses ovulasi akan tertunda atau malah terjadi lebih awal. Salah satu penyebab yang dapat mengganggu proses ovulasi yaitu stres.

Apabila didalam diri seorang wanita terus menerus mengalami tekanan dalam hal ini stres maka akan semakin memperberat gejala dari sindrom premenstruasi yang dia rasakan.

\section{KESIMPULAN}

Ada hubungan antara tingkat stres dengan sindrom premenstruasi pada mahasiswi DIII kebidanan semester 2 Universitas 'Aisyiyah Yogyakarta $(\mathrm{p}=$

\section{DAFTAR PUSTAKA}

1. Suparman E. Premenstrual Syndrome. EGC; 2012.

2. Kamaruddin $M$, Haerani, Ningsih $S$, Anjeli AMR. Deskripsi Pengetahuan Remaja Putri tentang Dismenore di Kelurahan Benjala Kecamatan Bontobahari Kabupaten Bulukumba. FK UNISA Palu. 2020;2(2):197-206. doi:10.31219/osf.io/qf4yu

3. Saryono, Sejati W. Sindrom Premenstruasi. Nuha Medika; 2009.

4. ACOG. Menstruation in Girls and Adolescents: Using the Menstrual Cycle as a Vital Sign. The American College of Obstetricians and Gynecologists. Published online 2015. 
5. Delara M, Ghofranipour F, Azadfallah P, Tavafian S, Kazemmejad A, Montazeri A. Health Related Quality of Life Among Adolescents with Premenstrual Disorders: a cross sectional study. Health and Quality of Life Outcomes. 2012;10(1):1-5.

6. Emilia O. Promosi Kesehatan dalam Lingkup Kesehatan Reproduksi. Pustaka Cendekia Press; 2008.

7. Kamaruddin M, Jusni, Nurul A Sari. Persepsi dan Pengetahuan Mahasiswa Akademi Kebidanan Tahirah Al Baeti terhadap Gizi Remaja. 2019;1(3):108112.

8. Kamaruddin M, Hasrawati, Usmia S, Jusni, Misnawaty, Handayani I. Korelasi antara Status Gizi dan Kadar Hemoglobin pada Kejadian Anemia Ibu Hamil Trimester III. JMA. 2019;1(2):77-82.

9. Departemen Agama RI. Al-Qur'an dan Terjemahan. Kementerian Agama RI; 2016.

10. NIH. Premenstrual Syndrome. Published online 2014. http://www.nlm.nih.gov/medimeplus/pre menstrualsyndrome

11. Nasution, Kemala I. Stres pada Remaja. USU Repository. Published online 2007.

12. Kusmiran. Kesehatan Reproduksi Remaja Dan Wanita. Salemba Medika; 2014.

13. Kamaruddin M. Trik Pencegahan dan Mengatasi TORCH pada Ibu dan Bayi Melalui Natural Products. Published online March 2019. https://www.researchgate.net/publication/ 334193275_TRIK_PENCEGAHAN_DA N_MENGATASI_TORCH_PADA_IBU _DAN_BAYI_MELALUI_NATURAL_ PRODUCTS 